\title{
Organization/Literature: Exploring the Seam
}

Christian De Cock $^{1}$ and Christopher Land ${ }^{2}$

\footnotetext{
${ }^{1}$ University of Exeter, UK

${ }^{2}$ University of Warwick, UK
} 


\title{
Organization/Literature: Exploring the Seam
}

\begin{abstract}
In this paper we develop a particular way of understanding literature and organization with the aim of drawing on and extending the relationship between the two. Hence our subtitle: exploring the seam. Although the use of literary concepts and theories within our discipline is now well established, the way in which such ideas are taken up often neglects debate and contestation by treating 'literature' as a relatively homogeneous field. By following some of the ardent debates relating to issues of representation, the relation between text and extra-textual reality, and literature's disclosure of its status as fiction, we find a discussion of (social) organization at the heart of contemporary literary theory. It is the oscillation between literature and organization that structures this paper and gives us our argument: that 'organization' and 'literature' are mutually co-articulating and interdependent concepts and fields of enquiry.
\end{abstract}

Keywords: organization, literature, fiction, interdisciplinarity, representation, narrative 


\section{Organization/Literature: Exploring the Seam}

\section{Introduction}

It is perhaps a commonplace that organization is not the dispassionate, rational, technical phenomenon it was once (supposedly) assumed to be. Even that most rational of organizational models, the bureaucracy, has been refigured not only as a dehumanizing machinery, productive of huge irrationalities (Bauman 1989) but also as a specifically gendered phenomenon (Ferguson 1984) and hotbed of desire, passion and perversity (Burrell 1997). Rather than a consummate rational engineer or scientist, Frederick Taylor has become a monster of the organizational imagination, tortured and driven by nightmares where he was trapped in the workings of a huge machine; the result, an obsessive compulsive working out of his neuroses in the organization of work. Studies of culture and organizational symbolism have alerted us to the centrality of meaning in the constitution of organization (Martin and Frost 1996; Parker 2000); thoroughgoing social-constructivists have refigured technology as a textual phenomenon (Grint and Woolgar 1997; Joerges and Czarniawska 1998); issues of identity, meaning and subjectivity have revolutionized traditionally objectivist studies of the labour process (O’Doherty and Willmott 2001); and to assert that metaphors are central to understanding organization now has become a platitude (Oswick et al. 2002).

Given these increasing concerns within the field of organization studies (OS) for all things literary - meaning, metaphor, textuality, desire and pleasure - it is logical that theorists of organization are turning to studies of literature for inspiration and insight. This first part of the paper reviews this turn to the literary through a brief overview of three modes of engagement: the importing of ideas from literary criticism, the use of literary modes of representation for the production and presentation of organizational knowledge, and the use of great literature to exemplify organizational issues and to educate management practitioners and students. Whilst OS as a field undoubtedly has benefited from the realisation that "good [organizational] theory requires using many of the same methods as good literature” (Elsbach et al. 1999: 633), one could legitimately ask what more there is to add to some of the seminal work in this area. We suggest new 
avenues of research can be opened up if we, however tentatively, shift the perspective from asking what the literary can do for organization theory by searching for sensitising devices/inspiration/methods which can improve knowledge production in the home discipline. Our paper proposes a form of engagement less unilateral and more akin to a mutual dialogue or perverse exchange of fluids with all its associated risks and dangers: academic debate as a kind of viral contagion through passionate embrace. By exploring the seam ostensively separating the literary and the organizational we ask what the two disciplines might do to each other.

We attempt to delineate some elements of the organization/literature relationship by examining moments of antinomy and equivalence in the second part of our paper. We first consider the self-disclosed fictional nature of the literary text and the self-professed factuality of the organizational text. As we shall argue, even this seemingly simple antinomy conceals an underlying equivalence: a concern to affect social reality. Following this we explore an apparent equivalence: the preoccupation of both the organizational and the literary fields with narrative. Beneath this common interest, however, we find scholars approaching the phenomenon of narrative from very different directions. Whilst organization theorists are happy to borrow frameworks and terminologies of what as appears to be a coherent body of (literary) theory, literary theorists studying narrative continue to grapple with fundamental problems of social organization and its relation to the textual. Through our exploration we point to the dynamic tensions and incongruities that flow from this organization/literature relationship, thereby furthering an engagement between the organizational and the literary that neither reduces one to the other, nor privileges their separation.

\section{Organization and Literature}

The use and study of literature in the social sciences has a long pedigree stretching back at least as far as Karl Marx’s references in Capital to literary works like Robinson Crusoe (1976: 169) or Goethe’s Faust (1976: 161; 180; 302; for an extensive overview of Marx’s use of literature see Prawer 1976). More recently, classics of organization studies to use literature have included William Whyte's (1956) study of The 
Organization Man, which contains two chapters on 'The Organization Man in Fiction' analyzing contemporary ideological shifts in individuality and identity through a critique of themes in mainstream popular fiction. Another significant landmark is Dwight Waldo's (1968) The Novelist on Organization and Administration where the suggestion that managers can learn from novels is first made explicit. Since the 1980s there has been a more systematic, concerted and sustained debate around the relationship between organization and literature that can be traced back to the emergence of studies of culture and organization and in particular the influence of anthropology and ethnography (Van Maanen 1998; Zald 1996). In the 1990s this interest bloomed with a whole series of papers engaging with the literary in a variety of ways. For purely heuristic purposes such studies can be split into three distinct modes of engagement: the use of literary criticism as an inspiration for the reformation of the discipline of organization studies (Hatch 1996; O’Connor 1995; Rhodes 2000); the use of literary genres as alternative modes of representation for organizational knowledge and research (Akin 2000; Watson 2000); and the use of literature as a tool for explicating organizational theory (De Cock 2000; Grey 1998; Ten Bos and Rhodes 2003; even Buchanan and Huczynski 2004) or for improving the practice of management and management education (Bloom 2001; Czarniawska-Joerges and Guillet de Monthoux 1994; Knights and Willmott 1999).

\section{Mode One - Literary Criticism and Organization Theory}

In the first mode of engagement the traditional divide between the social sciences and the humanities is dissolved as writing on organization is treated as a form of 'literature' equally subject to critique using literary theory as a play by Shakespeare or the novels of Zola. As Easton and Araujo put it: “...theoretical writing can be treated as literature in the sense that it can be fruitfully subjected to literary criticism” (1997: 100). For these scholars, this mode of criticism offers a fruitful alternative in the continuing debates over 'methods': “Acknowledging that our research is literature (don't we call it that all the time?) gives us another way of assessing our work” (Smircich 1992: 231). In borrowing both the models and the vocabulary of reflection from literature and literary theory the hope is that "organization studies will become more skilful in crafting their own narratives” (Czarniawska 1999: 21). In reflecting on the literary devices by 
which they, wittingly or unwittingly, construct their research accounts (in using, for example, particular plots or basic narrative tropes and genres) organizational scholars can improve their reading and writing skills.

To an extent this reflexivity has now been achieved in much of OS, raising the question of how to move on from this groundwork. To further this reflexivity Oswick et al. (2002: 295) recently argued that organizational scholars should move beyond established tropes (metaphor, metonymy, synecdoche) which form part of "cognitive comfort zone” and explore more exotic tropes (irony, anomaly) as these would provide “a more creative basis for knowledge generation in organizational science”. However, as Heracleous (2003: 191) pointed out in a reply article, “irony and anomaly are useful in knowledge generation in the same way metaphors are: as a way of either revealing previously unseen connections, associations, or correspondences or constituting new ones”. The belief that particular literary tropes will allow us to generate 'better' or 'more creative' organizational knowledge places us in a somewhat precarious situation. In hunting for new tropes, genres, plots and analytical frameworks to improve organizational knowledge, researchers may lose sight of the main contribution of these loans from literary theory, namely that they "will problematize organization theory, thus enabling it to reinvigorate itself” (Czarniawska, 1999: 12). Without fundamentally unsettling itself, OS may miss out on some of the possibilities for renewal contained in its engagement with literary theory. But if the home discipline is so unsettled then there is a problem of how to articulate a contribution that does not strictly build upon what went before. To understand 'improved knowledge' and 'progress' it is therefore useful to refer to the “disconnected yet coherent sequence of bolder and bolder sorties” Geertz outlined in the context of cultural studies:

Studies do build on other studies, not in the sense that, better informed and better conceptualized, they plunge more deeply into the same things... A study is an advance if it is more incisive - whatever that may mean - than those that preceded it; but it less stands on their shoulders than, challenged and challenging, runs by their side. (Geertz 1973: 25)

It is through this kind of engagement that we hope this paper contributes both to the debates over literature and organization, and to OS more broadly. 


\section{Mode Two - Literary Modes of Representation and Organization Theory}

The second mode of engagement between literature and organization is the use of literary modes of representation for the production and presentation of organizational knowledge. In a classic of this mode, When the Sleeper Awakes, John Jermier offers the reader a short story detailing the working day of Mike Armstrong from two perspectives (Jermier 1985). In the first version of the story, 'The Dream', Armstrong appears to be in control of his own destiny and enjoying life, and in particular, the creature comforts afforded to him by his position as a worker in a relatively affluent, industrial society. In the second reading of Armstrong's day '... The Nightmare', the previous comfort and harmony are replaced by antagonism and conflict. Other interesting examples include Akin’s (2000) and Mintzberg and Westley’s (2000) efforts at 'creative nonfiction’ (taking the form of 'a day in the working life of...'), Latour's (1996) scientifiction, and Watson's (2000) ethnographic fiction science.

At its very best this kind of work "invites consideration of similarities and differences between literary texts and texts produced by empirical organizational researchers. That is, it provokes thinking about written representations of organizational life as a literary genre and raises questions about the writers' commitments, the purpose(s) of writing, and the relation of literature to society" (Jermier 1992: 217). Yet, there is a danger that this particular mode of engagement may prove counterproductive in that it provides for a nonserious reading of the text, which thus may be safely ignored, or at least pigeonholed as merely "a species of entertainment to which the proper response is only a bellylaugh - or a groan” (Ashmore 1989: 209). Indeed, as Agar (1995) pointed out in his discussion of creative nonfiction in ethnography: the shift to writing styles based on imaginative construction and dramatic representation of (organizational) events, persistently raises issues of credibility when laid over a process whose claim is that the story is about real people doing real things. It is precisely this fundamental tension, “a consequence of packing factual content into fiction form, where the form requires some details and structures that readers and critics plausibly suspect the world did not provide” (Agar 1995: 124), that is often neglected in this mode of engagement. 
Furthermore, whilst the best examples are clearly interesting and raise significant problems for the methodology of organizational research and writing, they nevertheless remain within the logic of subordinating literary writing to a logic of representation where that which is represented is a knowledge of organization. To return to Jermier's tale of Mike Armstrong: whilst this can be read as demonstrating how "the story of a life would be told differently from the standpoints of different paradigms" (Smircich 1992: 229), thereby unsettling a foundational model for organizational knowledge, it is fairly clear to the reader that the 'awakened' version is the more nuanced, subtle and 'realistic' version of Armstrong's life (Martin 1992: 237). As such the story is not so much a pluralistic use of literature to present alternative paradigmatic readings as a use of literature in the defense of a specific theoretical reading of organization; in this case of a critical-theory inspired reading of alienation (Jermier 1985: 74-78).

\section{Mode Three - 'Great' Literature and Organization Theory}

The subordination of literature to the organizational is perhaps most obvious in writing which takes 'great' literature as a resource for the education of managers and the improvement of management practice. This use of literature as a resource for managerial practices often can be politically conservative in the sense of seeking to reproduce the dominant structures of managerial society, albeit with a heightened degree of effectiveness. For example, on $2^{\text {nd }}$ October 2003 BBC Radio 4 broadcast a feature on the Unilever company reading group where novels to be discussed were chosen by senior management. Even those texts which aspire to educating critical organizational scholars fall into the logic of colonialism that sees literature serving organization. In Management Lives, for example, Knights and Willmott (1999) seek to use novels as an 'aid' for students to understand better problems of organization and management. The authors even provide helpful plot synopses of the texts they consider in the appendices so that students do not have to read the originals. The suggestion here seems to be that anything 'literary' about the forms of presentation in these texts is irrelevant and all that really matters are the facts of the case and the thematic content of the text (Jones 2002). In general these moves imply a notion of literature as superfluous 
and ornamental but, significantly, also a notion of organization theory that is fixed and self-confident.

Other writers seem less confident about organization theory, even seeking to dethrone it in favour of literature, but retain a tendency to subordinate the literary to the organizational in the very act of valorising literature. For example, following a discussion of the ways in which the dominant treatment of organizational texts as nonliterary produces "humanoid word processors without judgmental skills”, CzarniawskaJoerges and Guillet de Monthoux suggest that:

Such 'one dimensional' readers will hardly provide our organizations and economies with enthusiastic leadership and imaginative management. To avert the risk of both cultural and emotional superficiality, it is useful to rediscover the novel as a more comprehensive route to managerial understanding. (Czarniawska-Joerges and Guillet de Monthoux 1994: 7)

Although literature, or at least the realist novel, is praised here for its realism, it is nevertheless subordinated to the needs of 'civilization', the economy and organization (cf. Domagalski and Jermier 1997; Waldo 1994: ix; 1968). 'Realism' is equated with better understanding and 'better management', but the ideological commitments of 'great literature' are left unexplored despite a wide ranging critique of such from within literary theory (e.g., Culler 1997; Eagleton 1996, 1998; Jameson 1981).

\section{Broaching the Great Divide?}

Whilst each of these three modes offers an analytically distinct way of engaging with 'literature', this typological heuristic has obvious limitations as the modes are not entirely separable in practice. The use of literary genres in the performance of organizational knowledge already assumes a dissolution of the boundary between the social sciences and the humanities (Linstead 2003; Zald 1996), and the notion that managers can benefit from exposure to great literature simultaneously assumes that these managers, and organizational analysts, should become conversant with the methods of literary criticism (Jermier and Domagalski 2000). Both of these assumptions draw attention to, and question the continued existence of, the boundary between the humanities and the social sciences. By seeking greater traffic across the 
great divide between the sciences and the arts, the liminal status of the social sciences is drawn to the fore. Whether this traffic involves the transport of methods or of objects of enquiry, the humanities and the social sciences are brought closer together by claiming a pre-existent continuity concerning the ontology of the social. Either, following a broadly postmodern narrative turn (Van Maanen 1998), the social as object is refigured as a textual phenomenon, subject only to interpretation and reinterpretation (Grint and Woolgar 1997), or the human is understood as a story-telling subject whose main activity is the construction of narratives (Czarniawska 2004; Gabriel 2000). In either case authors or researchers lose their privileged position because the social sciences, or even the natural sciences, are only one amongst many competing interpretations of the world and have attained their dominance through the co-implication of power and knowledge rather than through a strictly epistemological superiority (Foucault 1980). In this sense, the turn to literature in each of these modes opens onto a radicalized ontological pluralism where anything goes and thus has political as well as ontological and epistemological relevance for the study of organization (Martin 1992). All too often, however, this political radicalism is lost in the specific uses of literature in organization studies. This is at least partly due to a tension inherent in any interdisciplinary project. By seeking to break down disciplinary boundaries through engagement with another discipline, the very borders that scholars are seeking to collapse have to be assumed a priori (Weber 2001). This simultaneously gives too great a coherence to the 'other' and inadvertently shores up the identity of the home discipline.

In summary, what the various approaches discussed above share is a desire to subordinate the literary to the organizational. This is the case even when the stated aims of a particular text might be to break down the grounds upon which a clear distinction between literature and organization studies can be articulated (e.g., Czarniawska 1999; Rhodes 2001). In the most valuable contributions, whatever their mode of engagement, the use of philosophical, critical, and literary resources is exemplary, bringing these artefacts into another arena where their comprehensibility is made possible within previously demarcated spheres of interest and enquiry: what does this mean for 'us' organizational scholars? They demonstrate most clearly what OS has to gain from 
using literary and critical resources. Indeed, this subordination is inevitable if 'we' students of organization are to be able to say anything about literature without lapsing into an incomprehensible and uncomprehending silence in the face of literature as the Other. Yet, there are in-built limitations to an approach where the ultimate message is one of 'using' literature and criticism to 'improve' studies of organization. This is best exemplified in some organizational scholars succumbing to the "Look, Ma, there is a metaphor/narrative” syndrome (cf. Czarniawska 2004: 41) or turning into trope and genre hunters (incidentally, this way of proceeding is not peculiar to OS - viz. Culler (2001) and Eagleton (1996) for a critique of literary criticism from within). If we are to keep alive the radical potential of the literary turn, we may have to enter into a more dialogical relationship with the literary where "experiences between theory makers can be exchanged on a more equal footing” (Czarniawska 1999: 57). From this perspective the tension between organization and literature is irresolvable. Whilst each implies the other, it is the 'seam' along which their co-constitution is articulated which gives shape to each. The relationship between organization and literature is thus both undecidable and constitutive of both realms of activity. In tracing this relationship along its seam, the rest of this paper aims to "run by the side" (Geertz 1973: 25) of the texts and approaches discussed so far, challenged by and challenging them, so as to explore their limits and thereby extend what we see as a potentially extremely productive engagement (though, as will become clear, we cannot be certain what will thereby be produced...).

\section{Antinomies?}

Conventional organizational texts often refer to the facts of 'objective' reality: processes, hierarchies, resources, strategies, managers and employees etc. What these 'normal' discourses often seem to conceal, however, is their own fictionality (Bedeian 1997; Knorr Cetina 1994). Literary texts, on the other hand, contain a range of signals to denote that they are fictive, the most obvious and most durable of such signals being literary genres. Our point is not simply that all texts are constructed (rather than being a simple mirror held up to the world), nor even that they are fictitious, but that fictional literature acknowledges this whilst other types of writing conceal their fictional origins. As Wolfgang Iser writes: 
It is a commonplace that the fictive is not confined to the literary text. Fictions also play vital roles in the activities of cognition and behavior, as in the founding of institutions, societies, and world pictures. Unlike such nonliterary fictions, the literary text reveals its own fictionality... In the self-disclosure of its fictionality, an important feature of the fictional text comes to the fore: it turns the whole of the world organized in the text into an 'as-if' construction. In light of this qualification (implicitly accepted the moment we embark on our reading), it is clear that we must and do suspend all natural attitudes adopted toward the 'real' world once we are confronted with the represented world... Just as the incorporated 'real' world is bracketed off, so too are our natural attitudes. (Iser 1993: 12-13)

For Iser, this self-disclosure points to a differentiation of the functions of the literary text and those texts and activities that seem focused on the 'real'. Whilst the latter must conceal the artifice of their origins in order to remain effective as foundations for social organization, and therefore make explicit promises as to what a given text should achieve (Czarniawska 1998: 77), literary fiction has the potential to radically critique this social organization by explicitly pointing to "something that it is not" and "to make that something conceivable” (Iser 1993: 13).

Roland Barthes' distinction between the écrivant (writer) and the écrivain (author) helps to elucidate this point. The writer of organizational texts, be it an academic or practitioner, is what Barthes (1982) would call an écrivant. For the écrivant the verb 'to write' is transitive. He posits a goal (to give evidence, to explain), for which his writing is merely a means. For him language supports a praxis, it does not constitute one. His writing is an instrument of communication. The écrivant's writing can be produced and consumed only in the shadow of institutions which have, originally, an entirely different function than to focus on language: the organization, scholarly research, politics, etc. What defines the écrivant is the fact that his project of communication seeks to resolve an ambiguity and institute an irreversible explanation. For the écrivain or literary author, it is the other way around: she knows that her writing, intransitive by choice, inaugurates an ambiguity. Because the verb ‘to write' is intransitive for her, writing can never explain the world. Indeed, this is "a kind of writing in which you can neither lie, tell the truth nor make a mistake” (Eagleton 2004: 90). That is why literature is always unrealistic. However, this is not to dismiss its significance for social organization. As Barthes argues: 
its very unreality permits it to question the world, though these questions can never be direct... what he [the écrivain] obviously gains is the power to disturb the world, to afford it the dizzying spectacle of praxis without sanction. (Barthes 1982: 187-188)

For Barthes literature’s 'unreality’ is the very source of its power to affect reality. Our apparent antinomy (fiction/real; concealment/disclosure) thus conceals a deeper equivalence. Precisely by consciously entering the "kingdom of fiction”, the configuration of language in its own space, literary texts acquire the power to effect changes in the real, to restructure the world of the reader in unsettling and challenging ways, something that Ricoeur referred to as the power of refiguration:

The thesis that I maintain is that language's power of refiguration is proportional to its power of distanciation in the moment of its self-constitution in the universe of the signifier. This is the general thesis, the front on which I have always fought: language, in my opinion, means (veut dire) the world because it has first left the world; in this way it initiates a movement of reconquest of the reality lost by the prior conquest of meaning in itself and for itself. (Ricoeur 1998: 87)

Whilst (social) scientific texts operate more or less directly, literary and poetic texts operate in a more subtle, more indirect manner, inasmuch as the chasm between language and reality has reached much greater depths. As the representational function is lessened, the biting power of the work on the world of our experience is reinforced: "the greater the retreat, the more intense the return back upon the real..." (Ricoeur 1998: 176). Paradoxically, in trying to subjugate the literary to the organizational we diminish its power to effect changes in the real. In our 'instant-everything' rush to make literature usable for the 'real' world, we fail to exploit its true power, which follows precisely from its self-disclosure as fiction: as a text that explicitly does not represent an external reality.

Czarniawska (1998: 5) is correct in stating that "there are no fundamental structural differences between fictional and factual narratives” (also, see Case 2003), but it certainly does not follow that we can therefore safely bypass the whole fact/fiction issue. To paraphrase Eagleton (1996: 125), to say that there are no absolute grounds for making the distinction between 'fact' and 'fiction' is not to say that these words lack meaning or are ineffectual. Indeed, the controversy surrounding many textual experiments in OS centres around the suspicion that "aesthetic concerns dominated the 
factual, that the structured, scenic presentation of powerful new events led to loose play with what had actually happened” (Agar 1995: 119). Whilst Czarniawska, in a recent book (2004: 9), points out that "the lack of structural difference between fictional and factual narratives is suspected to account for most of their power”, it is only when considering the matter of function that we can begin to explain this power. Following Iser, Barthes and Ricoeur we have suggested that it is precisely the difference in function between (social) scientific and literary texts that adumbrates a deeper equivalence. The incision between literary text and world (which hinges on the text's self-revelation as fiction) must be made decisively to come to this equivalence: the power of both kinds of texts to affect changes in the real. This puts into question the prevalence of the 'Realist' novel in the mode three types of engagement with literature. Czarniawska aptly summarizes this dominance:

For organization theorists, realism may be the most attractive style in which to present their knowledge, because it is both legitimate and expected. The question is then not 'Whether realism?' but 'What kind of realism?' (Czarniawska 1999: 59)

What Czarniawska sees as a strength of the realist novel, that the advice can be taken directly into studies of organization, is also a weakness. As Iser (1993) suggested, selfrevelation as fiction withdraws authenticity from whatever form it may take and it is precisely this lack of 'authenticity', its ambiguity and 'strangeness' that provides the strength of the literary text (cf. De Cock 2000).

Of course, from such a point of view, it is quite impossible to conceive of using literature to serve organization studies. This very idea requires that knowledge can be carried as a representation from one domain into another whilst leaving the latter quite intact. We might argue that literature is not so much concerned with the representation of the world, either as it is or as it could be, as with the expression, creation and production of that which is not (Calvino 1987). It gives us other worlds and becomings and does so not by being a copy of the actual world but by extending the virtual tendencies of the given world (Miller 2002). By being attentive to the production of the real - including social behaviours and institutions - the literary actively extends the material world. A greater awareness of this deep equivalence between the literary and social organization would assuage Deetz's concern that by only superficially heeding 
the literary turn we have missed important new ways to think through problems of organizational life:

Most of these studies look at texts and talking rather than looking through discourse to see the specific ways the world is produced. The problem of language as the 'mirror of nature' that preoccupied the positivists was replaced by simply focusing on the 'mirror' as an object. The central 'turn' issues of how different worlds emerge, the power relations in this emergence, and the mechanisms of protection got lost. (Deetz 2003: 425)

What appears initially as a radical difference between organization and literature reappears as a common set of problems in both the humanities and the social sciences. The humanities are not necessarily better equipped to solve these problems, however, as is evinced, for example, by Murphy's (1997) use of conventional social scientific resources like actor-network theory, Jameson’s (1981) and Eagleton’s (1996, 1998) reliance on Marxism as their generative matrix, and Iser's (1993) turn to anthropology, to re-orientate literary theory.

\section{Equivalences?}

Probably the most intuitive area of convergence between literature and organization is the prevalence within both areas of a concern with narratives. As Yiannis Gabriel writes in the preface to a recently edited book:

Writing or telling a narrative is not so fundamentally different from resolving a crisis or reorganizing a set of resources. The quest for meaning characterizes organizing, consuming, and producing as well as purely narrative acts. (Gabriel 2004: xi)

Writers like Gabriel and Czarniawska have argued extensively for the value of narrative modes of knowing for organization studies. Stories, so the argument goes, are the main way we make sense of things, whether in thinking of our lives as a progression leading somewhere or in telling ourselves what is happening in the world. Boje’s (1991; 2001) 'storytelling organization theory' takes as point of departure that narratives are the organization. This is because humans are storytelling animals who act toward their organization and environments based upon their storied interpretations of self, other, organization, and environment. Narrative projections and productions of the self through career, C.V. and identity are central to the organization of contemporary production as well as the production of organization (Casey 1995; Grey 1994). Indeed, 
it is in the contestation over the resources for the construction of narratives of the self that many of the contemporary skirmishes over control and resistance in the workplace are fought (Fleming and Spicer 2003).

Whilst the study of narratives and stories seems to be in rude health in organization studies (and the social sciences more widely - see Czarniawska 2004), its current status in the discipline of literary studies is not so clear-cut. Culler (2001), in a newly written preface to his classic The Pursuit of Signs, indicates that whilst much work has been done in the field of narratology (too much to attempt any sort of synthesis in a few pages), this area of study has languished since the heyday of structuralism in the 1960s and 1970s. As an aside: it seems somewhat ironic that whilst much of the interest in narrative and stories entered organization studies on the back of the postmodern and post-structural turn, the initial impetus behind much of the theories on which the work of these researchers relies flows from the energizing role of French structuralism which granted a pivotal role to the modernist novel (e.g. the novels of James Joyce, Virginia Woolf, Alain Robbe-Grillet). These modernist works usually contain no unified narrative voice, but move instead by continuous rapid jump-cutting, cross-cutting or montage (Berman 1983). It is precisely this avant-garde literature, sometimes referred to as 'anti-narrative', that poses the most fundamental questions with regards to how we identify plots, narrative sequences and characters; how we recognize satisfactory endings, in short, challenges “our habitual ways of making sense” (Culler 2001: xiv).

Czarniawska humbly admits she uses “a narrow definition of narrative” (1998: 2) based on three elements - an original state of affairs, an action or event, and the consequent state of affairs - and a plot that brings them into a meaningful whole. Whilst she treads carefully and broadly succeeds in her aim of problematizing traditional ways of proceeding in OS, others have made far more debatable sorties. A particular source of inspiration for organization theory (e.g., Barry and Elmes 1997; Jeffcutt 1994; Sköldberg 2003) has been the theoretical edifice of Northrop Frye (1957). However, what remains unacknowledged in work of this kind is that Frye's system is far from uncontroversial in its home discipline and is often viewed as a most conservative approach (Culler 2001: xx), the appeal of which lies in its combination of "an extreme 
aestheticism with an efficiently classifying 'scientificity”” (Eagleton 1996: 81), leading to a "mighty totalization of all literary genres" (ibid: 79). Frye's assumptions were that literature works by certain objective laws (the various modes, archetypes, myths and genres by which all literary works are supposedly structured), that criticism could itself become systematic by formulating them, and that at the root of all literature lay four narrative categories: the comic, the romantic, the tragic and the ironic. Frye (1957: 122) insisted that literature is an "autonomous verbal structure” quite cut off from any reference beyond itself, an inward looking realm which "contain[s] life and reality in a system of verbal relationships”. Eagleton (1996: 80) pointedly remarked that literature, for Frye, has no relation to any kind of reality outside it, but rather is a kind of "collective utopian dreaming which has gone on throughout history". Frye hence seems a rather odd choice as companion for organizational scholars given that most work on narrative in literary theory is ultimately concerned with the reality outside it.

Indeed, if there is one crucial issue various theorists of narrative - from Barthes to Todorov; from Genette to Ricoeur - agree on, it is that to make narrative an object of study, one must distinguish narratives from non-narratives, and this invariably involves reference to the fact that narratives report sequences of events. In other words, the theory of narrative requires a distinction between the story as a sequence of actions or events (the fabula in the vocabulary of the Russian Formalists), something which exists prior to and independently of narrative presentation and which the narrative then reports, and the discursive presentation or narration of events, the story as reported in the narrative (the sjuzhet). Thus every narrative operates according to a double logic, presenting its plot as a sequence of events which is prior to and independent of the given perspective on these events, and, at the same time, suggesting by its implicit claims to significance that these events are justified by their appropriateness to a thematic structure. For example, Freud's case histories are narratives with a fabula and a sjuzhet: the fabula is the sequence of events in the patient's life, and the sjuzhet is the order in which these events are presented, the story of Freud's conduct of the case. Even the most radical fictions of a Burroughs or a Robbe-Grillet depend for their effect on the assumption that their puzzling sequences of sentences are presentations of events (though we may not be able to tell what those events are and in what order they 
occurred). It is precisely the assumption of a real order of events that makes the repetitions of the narrative discourse confusing and challenging in these works. In other words, it is the organization of events in the real that allows readers to describe the narrative presentation as a modification or effacement of the order of events.

The dialectic between the priority of events and the determination of events by structures of signification makes for a structure of undecidability and it is here that we find our seam again; it is impossible to decide what organizes what: "Even when one tries to assert the primacy of either word or deed, one does not succeed in escaping the alternative one tried to reject” (Culler 2001: 204). It is precisely when the dialectic loses its balance that literature either becomes a simple prop to embellish organizational research papers or, conversely, a means of demonstrating that the world is essentially impenetrable. In either case the literary 'game’ would no longer work as challenge to understand the world (Calvino 1987). The wider implications of this undecidability have not really been explored, possibly because it would require us to take a firm step outside of disciplinary grids. Such a move might both re-invigorate the field of narratology (and literary theory more widely) and induce organization theorists to realize that literary studies does not simply present a coherent body of theory through which they can simply run yet more organizational texts. It also raises a further question which opens up interesting lines of thinking: "Is narrative a fundamental form of knowledge (giving knowledge of the world through its sense-making) or is it a rhetorical structure that distorts as much as it reveals?”(Culler 1997: 92).

In literary studies the recent norm is no longer the appreciative interpretation of individual literary works that our 'mode one' researchers find so inspiring. Interpretation has remained a key concern, but the focus has shifted to its symptomatic dimensions, taking the literary work as "the symptom of a condition or reality thought to lie outside it" (Culler 2001: xvii), "making it into a divining rod for the hidden dimension of social organizations and relationships” (Iser 1993: x). From such a perspective, "the literary or aesthetic act... always entertains some active relationship with the Real” (Jameson 1981: 67). For example, the key argument of Jameson’s (1981) classic, The Political Unconscious, is that it is narrative, story-forms and plots, that play 
a dominant role in mediating individual experience and social organization, according to a process of what Jameson calls 'transcoding' - the translating into an accepted code (which consists of certain narrative patterns and expectations) of social and historical reality to make it accessibly mediated for the individual. For Jameson, narrative is a key mode of mediating not only between the individual and society, but also between the apparent fragmentation of society and the real totality underlying it. Literature thus inevitably refers back to and embodies the social and economic realities within which it was produced; this is to say that literature is historically contingent. Literature's authority at a particular time and place enforces ideological and therefore unconscious or 'unacknowledged' assumptions that govern behaviour in a particular society as taken-for-granted and universal (Miller 2002). But literature can also provide the place where ideology is exposed, revealed as something that can be questioned (Berman 1983). For long periods of time literature appears to work in favour of the confirmation of values, the acceptance of authority. But at a certain moment something is triggered and literature may give birth to a movement in the opposite direction, refusing to see things and say things the way they have been seen and said previously (Calvino 1987). And, as Bourdieu (1991: 31) remarked, such an understanding of the socially instituted limits of the ways of speaking and thinking constitutes "the first step in creating new social relations, alternative ways of organising social and political life...”.

Of course, there are many literatures and their consumption as artefacts occupies a number of different social institutions. The literary is performed not only in the text, but within the textual relations of reading, writing, interpretation and criticism that constitute the organization of literature. To ask essentialist questions of what the purpose of literature is would be to reify a social relation as a fetish, not unlike the commodity (Marx 1976). But then such an interpretation is itself not simply theoretically naïve. It is produced within the specific social relations of late capitalism. Indeed, the production of narrative form can be seen as an ideological act in its own right, with the function of inventing imaginary or formal 'solutions' to irresolvable social contradictions (Jameson 1981: 64; following Lévi-Strauss’ seminal characterization of mythic narrative as the imaginary resolution of particular determinate real contradictions). This raises an additional ethical quandary of whether it 
should be our aim to organize the fragmentation of the world into another narrative, with all the traumata of that world properly sutured? Perhaps it is modernist, antinarrative literature that is the most 'realistic' in that it grasps "the unfolding, fragmenting, decomposing and increasingly shadowy realities of modern life” (Berman 1983: 257) in a world where capitalist society has become "increasingly dependent in its everyday operations on myth and fantasy, fictional wealth, exoticism and hyperbole, rhetoric, virtual reality and sheer appearance” (Eagleton 2004: 67; see also De Cock et al. 2005).

Literary narration, its disruption in modernist anti-narrative fiction, and the relationship between these literary forms and modes of social organization are clearly complex and interdependent. It is the ever-changing constellation of reader, text and author(ity) that determines the interpretation of modern literary forms (Iser 1993). As it is, the separation of these forms from the simultaneous deconstruction and re-articulation of ideology and socio-historical organization always will be impossible. Neither should we be tempted by a simple reduction, however, with literature serving an essentially conservative or revolutionary role. To make such claims of essence independent of organization would be to miss the basic point about the organization/literature relationship we have been trying to articulate in this paper.

\section{In Conclusion...}

This paper has considered afresh the question of the relationship between organization and literature that recently has come to preoccupy so many organizational theorists. Whilst many of these scholars have sought to learn from 'literature' or 'literary theory' conceived as a distinct domain or entity which can be mined for scarce resources that will enable us to theorize 'organization' more effectively, it has been our argument that this approach is somewhat self-limiting. We have suggested that one should beware of treating literary theory as a stable object, as an entity to which one must remain faithful. Like the human identities which shape and are shaped by literature and organization, neither of these fields is stable or unified. 
It is when we start to consider some of the more problematic debates unsettling the field of the literary that we come across a set of difficulties revolving around the issue of (social) organization. On our journey we encountered theorists whom, all in their own way, are exploring the literature/organization seam; for example, Iser's (1993) mapping of the relations between the fictive, the imaginary and the real, Jameson's (1981) concept of narrative as a mediator between individual experience and social organization, and Ricoeur's (1998) development of the dialectical relation between text and reality. Seeking illumination for our profane realm of organization we begged entry to the sacred temples of literature and found the prophets discussing... organization! Given the undecidability of the organization/literature relationship, this paper has pointed to a series of common articulations of problematics which might paradoxically raise the importance and estimation of studies of organization, rather than subordinating our discipline to an older and wiser, more revered humanity. But we are certainly not encouraging such a simple inversion. Whilst organization is doubtless at the heart of the literary, so literature is found (albeit repressed) at the heart of the organizational.

In focusing on the literature/organization seam, one could argue that we offer little in terms of tangible 'product' to either organizational practitioners or theorists. Yet, it is precisely the point of this paper that the real value of the literary turn lies in its capacity “of reflecting and provoking” (Czarniawska 1999: 3), not in offering frameworks and clearly delineated methods. Perhaps it is appropriate to let Italo Calvino, a novelist and literary theorist, provide the final words in this respect:

I find myself stating that I do believe in a type of education by means of literature; a type of education that can yield results only if it is difficult and indirect... Any result attained by literature, as long as it is stringent and rigorous, may be considered firm ground for all practical activities for anyone who aspires to the construction of a mental order solid and complex enough to contain the disorder of the world within itself; for anyone aiming to establish a method subtle and flexible enough to be the same thing as an absence of any method whatever. (Calvino 1987: 99) 


\section{References}

Agar, Michael

1995 'Literary journalism as ethnography', in Representations in ethnography, J. Van Maanen (ed.), 112-129. London: Sage.

Akin, Gib

2000 'Learning about work from Joe Cool'. Journal of Management Inquiry, 9/1: 5761.

Ashmore, Malcolm

1989 The reflexive thesis: Wrighting sociology of scientific knowledge. Chicago:

University of Chicago Press.

Barry, David and Michael Elmes

1997 'Strategy retold: Toward a narrative view of strategic discourse'. Academy of

Management Review, 22: 429-452.

Barthes, Roland

1982 A Roland Barthes reader. London: Sage

Bauman, Zygmunt

1989 Modernity and the holocaust. Cambridge: Polity.

Bedeian, Arthur

1997 'Of fiction and fraud: a comment on Barry and Elmes' article'. Academy of

Management Review, 22/4: 840-842.

Berman, Marshall

1983 All that is solid melts into air: the experience of modernity. London: Verso.

Bloom, Harold

2001 'A reading list for Bill Gates - and you’, Harvard Business Review, 79: 63-68.

Boje, David

1991 'The storytelling organization: a study of story performance in an office-supply

firm’. Administrative Science Quarterly, 36: 106-126.

Boje, David

2001 Narrative methods for organizational \& communication research. London: Sage.

Bourdieu, Pierre

1991 Language and symbolic power. Cambridge: Polity.

Buchanan, David and Andre Huczynski

2004 Organizational behavior: an introductory text, $4^{\text {th }}$ edition. Harlow: Pearson

Education. 
Burrell, Gibson

1997 Pandemonium: towards a retro-organization theory. London: Sage.

Calvino, Italo

1987 The literature machine. London: Vintage

Case, Peter

2003 'From objectivity to subjectivity: pursuing subjective authenticity in organizational research', in Debating organization: point-counterpoint in organization studies, R. Westwood, and S. Clegg (eds), 156-179. Oxford: Blackwell.

Casey, Catherine

1995 Work, self and society: after industrialism. London: Routledge.

Culler, Jonathan

1997 A very short introduction to literary theory. Oxford: Oxford University.

Culler, Jonathan

2001/1981 The pursuit of signs. London: Routledge.

Czarniawska Barbara

1998 A narrative approach to organization studies. London: Sage

Czarniawska, Barbara

1999 Writing management: organization theory as a literary genre. Oxford: Oxford University.

Czarniawska, Barbara

2004 Narratives in social science research. London: Sage.

Czarniawska-Joerges, Barbara and Pierre Guillet de Monthoux

1994 Good novels, better management: reading organizational realities in fiction.

Berkshire: Harwood Academic Publishers.

De Cock, Christian

2000 'Reflections on fiction, representation, and organization studies: an essay with special reference to the work of Jorge Luis Borges', Organization Studies, 21/3: 589609.

De Cock, Christian, James Fitchett and Christina Volkmann.

2005 'Constructing the New Economy: A discursive perspective', British Journal of Management, 16/1:

Deetz, Stanley

2003 'Reclaiming the legacy of the linguistic turn', Organization, 10: 421-429.

Domagalski, Theresa and John Jermier 
1997 'Review of: Good novels, better management: reading organizational realities in fiction’, Academy of Management Review, 40/1: 289-295.

Eagleton, Terry

1996 Literary theory: an introduction, 2nd ed. Oxford: Blackwell.

Eagleton, Terry

1998 Criticism and ideology: a study in marxist literary theory. London: Verso.

Eagleton, Terry

2004 After theory. London: Penguin.

Easton, Geoff and Luis Araujo

1997 'Management research and literary criticism', British Journal of Management, 8/1: 99-106.

Elsbach, Kimberly, Robert Sutton and David Whetten

1999 'Perspectives on developing management theory, circa 1999: moving from shrill monologues to (relatively) tame dialogues', Academy of Management Review, 24/4: 627-633.

Ferguson, Kathy

1984 The feminist case against bureaucracy. Philadelphia: Temple University Press.

Fleming, Peter and Andre Spicer

2003 'Working at a cynical distance: implications for power, subjectivity and resistance’, Organization, 10/1: 157-179.

Foucault, Michel

1980 Power/knowledge: selected interviews and other writings 1972-1977, C. Gordon (ed). Hemel Hempstead: Harvester Wheatsheaf.

Gabriel, Yiannis

2000 Storytelling in organizations: facts, fictions and fantasies. London: Sage.

Gabriel, Yiannis

2004 'Preface' in Myths, stories, and organizations. Y. Gabriel (ed). Oxford: Oxford University Press.

Geertz, Clifford

1973 The interpretation of cultures: selected essays. New York: Basic Books.

Grey, Chris

1994 'Career as a project of the self and labour process discipline', Sociology, 28/2:

479-497.

Grey, Chris 
1998 'Child's play: representations of organization in children's literature' in Organization/Representation: Work and organizations in popular culture. J. Hassard and R. Holliday (eds), 131-148. London: Sage.

Grint, Keith and Steve Woolgar

1997 The machine at work. Cambridge: Polity.

Hatch, Mary Jo

1996 'The role of the researcher: an analysis of narrative position in organization theory’, Journal of Management Inquiry 5: 359-374.

Heracleous, Loizos

2003 'A comment on the role of metaphor in knowledge generation', Academy of Management Review, 28/2: 190-191.

Jeffcutt, Paul 1994 'The interpretation of organization: a contemporary analysis and critique'. Journal of Management Studies, 31: 225-250.

Iser, Wolfgang

1993 The fictive and the imaginary: charting literary anthropology. Baltimore: Johns Hopkins University Press.

Jameson, Frederic

1981 The political unconscious: narrative as a socially symbolic act. London:

Routledge.

Jermier, John

1985 ' 'When the sleeper wakes': a short story extending themes in radical organization theory', Journal of Management, 11/2: 67-80.

Jermier, John

1992 'Literary methods and organization science: reflection on 'When the sleeper wakes' in Doing Exemplary Research. P. Frost, and R. Stablein (eds), 210-226. London: Sage.

Jermier, John and Theresa Domagalski

2000 'Storytelling and organizational studies: a critique of 'learning about work from Joe Cool’', Journal of Management Inquiry, 9: 62-64.

Joerges, Bertrand and Barbara Czarniawska

1998 'The question of technology, or how organizations inscribe the world', Organization Studies, 19, 3: 363-385.

Jones, Campbell

2002 'Impossibilities of reading: literature and organization', paper presented at The International Colloquium on Text and Economics, University of Antwerp, 16-18 May 2002. 
Knights, David and Hugh Willmott

1999 Management lives. London: Sage.

Knorr Cetina, Karin

1994 'Primitive classification and postmodernity: towards a sociological notion of fiction’, Theory, Culture \& Society, 11: 1-22.

Latour, Bruno

1996 Aramis or the love of technology. Cambridge (MA): Harvard University Press.

Linstead, Stephen

2003 'Introduction: text, organization and identity' in Text/Work: Representing organization and organizing representation. S. Linstead (ed), 1-12. London: Routledge.

Martin, Joanne

1992 'Escaping the inherent conservatism of empirical organizational research' in Doing exemplary research. P. Frost and R. Stablein (eds), 233-239. London: Sage.

Martin, Joanne and Peter Frost

1996 'The organizational culture war games: a struggle for intellectual dominance' in

The Handbook of Organization Studies. S. Clegg, C. Hardy and W. Nord (eds). London: Sage.

Marx, Karl

1976 Capital Volume 1. London: Penguin.

Miller, Hillis J.

2002 On literature. London: Routledge.

Mintzberg, Henry and Frances Westley

2000 'Sustaining the institutional environment', Organization Studies, 21/0: 71-94.

Murphy, Timothy

1997 Wising up the marks: the amodern William Burroughs. Berkeley: University of California Press.

O'Connor, Ellen

1995 'Paradoxes of participation: Textual analysis and organizational change'.

Organization Studies 16: 769-803.

O’Doherty, Damian and Hugh Willmott

2001 'The question of subjectivity and the labor process', International Studies of Management and Organization, 30/4: 112-132.

Oswick, Cliff, Tom Keenoy and David Grant

2002 'Metaphor and analogical reasoning in organization theory: Beyond orthodoxy,' Academy of Management Review, 27/2: 294-303. 
Parker, Martin

2000 Organizational culture and identity: unity and division at work. London: Sage.

Prawer, Siegbert Salomon

1976 Karl Marx and world literature. Oxford: Oxford University Press.

Rhodes, Carl

2001 Writing organization: (re)presentation and control in narratives and work.

London: Benjamin.

Rhodes, Carl

2000 'Reading and writing organizational lives', Organization, 7/1: 7-29.

Ricoeur, Paul

1998 Critique and conviction: conversations with François Azouvi and Marc de Launay (K. Blamey, Trans.). Cambridge: Polity Press.

Sköldberg, Kaj

2003 The poetic logic of administration: styles and changes of style in the art of organizing. London: Routledge.

Smircich, Linda

1992 'Stories of Mike Armstrong and the idea of exemplary research', in Doing exemplary research. P. Frost and R. Stablein (eds), 227-232. London: Sage.

Ten Bos, Rene and Carl Rhodes

2003 'The game of exemplarity: subjectivity, work and the impossible politics of purity’, Scandinavian Journal of Management, 19: 403-423.

Van Maanen, John

1998 'Different strokes: qualitative research in the Administrative Science Quarterly from 1956 to 1996', in Qualitative studies of organizations. J. Van Maanen (ed.), ixxxxii. London: Sage.

Waldo, Dwight

1968 The novelist on organization and administration. Berkeley: Institute of Government Studies.

Waldo, Dwight

1994 'Preface', in Good novels, better management: Reading organizational realities in fiction. B. Czarniawska-Joerges and P. Guillet de Monthoux (eds), ix-x. Chur:

Harwood Academic Publishers.

Watson, Tony

2000 'Ethnographic fiction science: making sense of managerial work and

organizational research processes with Caroline and Terry', Organization, 7: 489-510. 
Weber, Samuel

2001 Institution and interpretation: expanded edition. Stanford: Stanford University

Press.

Whyte, William

1956 The organization man. London: Pelican.

Zald, Mayer

1996 'More fragmentation? Unfinished business in linking the social sciences and the humanities’, Administrative Science Quarterly, 41/2: 251-261.

\section{Christian De Cock}

Christian De Cock is Senior Lecturer in Organization Studies at the University of Exeter. He received his MSc. and Ph.D. degrees from the University of Manchester. Prior to joining the School of Business and Economics he worked as a Research Fellow at Manchester Business School and as a Lecturer at the University of London. His research interests can be roughly divided into three broad areas: creativity and innovation; discourse and literary theory; and philosophy and social theory; in as far as these pertain to empirical and/or theoretical dilemmas in the field of organization studies.

\section{Christopher Land}

Christopher Land completed his $\mathrm{PhD}$ at Warwick University exploring the relationship between new technology and subjectivity through the writing of William S. Burroughs. Whilst he has on-going research interests in new technology, literature, and subjectivity, most of his work is currently focused on alternative forms of organization and contestation over the idea of 'community'. He is a visiting fellow at Warwick University and works as a freelance researcher, lecturer and bike mechanic. He lives in an anarchist community in the West Midlands of England where he works actively to foment radical social change. 